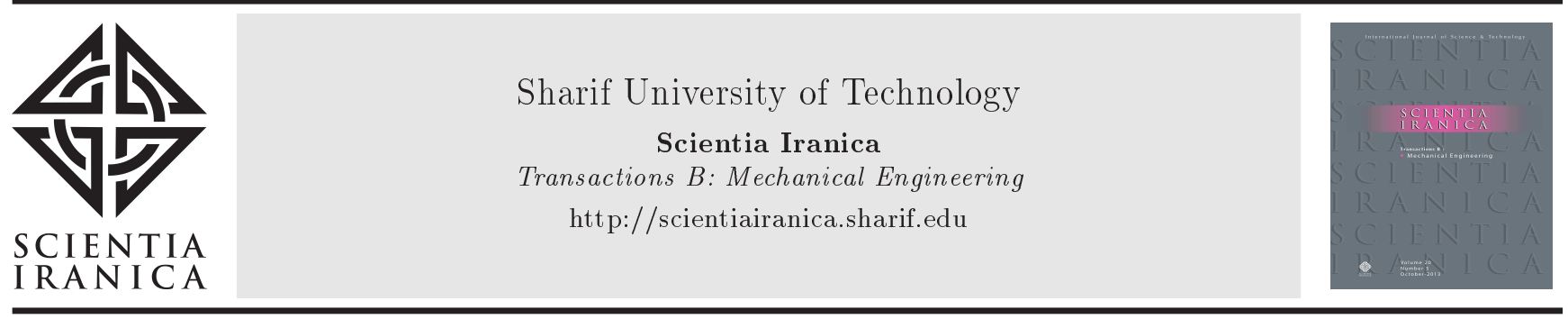

\title{
Performance and emissions optimization of an ethanol-gasoline fueled SI engine with oxygen enrichment using artificial bee colony algorithm
}

\author{
B. Beigzadeh*, A. Reihani, and A. Ojaghi \\ Biomechatronics and Cognitive Engineering Research Laboratory, School of Mechanical Engineering, Iran University of Science and \\ Technology, Tehran, Iran.
}

Received 25 September 2015; received in revised form 28 September 2016; accepted 2 January 2017

\author{
KEYWORDS \\ Ethanol fueled engine; \\ Alternative fuels; \\ Spark ignition engine; \\ Oxygen enriched \\ combustion; \\ Performance \\ improvement; \\ Emissions reduction.
}

\begin{abstract}
The use of artificial neural network in conjunction with artificial bee colony algorithm is proposed as a method for performance and emissions optimization of an SI engine. The case study here involves the oxygen enriched combustion of an SI engine fueled with hydrous ethanol and gasoline. In this study, the engine was considered as a black box and its performance and emissions were extracted experimentally at different intake air oxygen concentrations, hydrous ethanol injection rates, and ethanol concentration in the hydrous ethanol mixture. Then, the simultaneous injection of hydrous ethanol and oxygen enriched combustion was investigated to maximize the fuel conversion efficiency and minimize the $\mathrm{CO}$ and NOx emissions. Therefore, an objective function consisting of both the emission and performance parameters was optimized using the Artificial Bee Colony algorithm. The engine model used in this optimization process was obtained from an Artificial Neural Network trained with experimental engine data. For operating speed of $3000 \mathrm{rpm}$, the optimization results indicated $1.21 \%$ improvement in fuel conversion efficiency and $31.11 \%$ and $13.94 \%$ reduction in $\mathrm{CO}$ and NOx emissions, respectively. At the speed of $2000 \mathrm{rpm}$, fuel conversion efficiency improved by $4.11 \%$ and $\mathrm{CO}$ emission decreased by $18.73 \%$, while NOx concentration increased by $28.35 \%$.
\end{abstract}

(C) 2018 Sharif University of Technology. All rights reserved.

\section{Introduction}

Considering the rising trend of energy consumption in recent years and the limitation of the available energy resources and climate change, it is crucial to control and curb the utilization of energy. Road transportation consumes a substantial portion of energy in the form of fossil fuels; thus, it is necessary to improve the efficiency and fuel economy of vehicle engines. In

*. Corresponding author. Tel.: +9821 7r240094;

Fax: +9821 73021587

E-mail address: b_beigzadeh@iust.ac.ir (B. Beigzadeh) addition, the fossil fuel reserves in the world are limited and will be used up in the near future. Therefore, the use of alternative fuels seems to be inevitable [1]. Alternative fuels such as hydrogen, natural gas, and biofuels are considered as viable options for the transportation industry to help it reduce its dependency on fossil fuels [2].

In addition, current strong restrictions on emissions from road transportation along with the growing public awareness of the environmental and health impacts of exhaust emissions from vehicles have necessitated the use of biofuels such as ethanol [3]. Bioethanol is an alternative fuel, which can be produced from various kinds of biomass, such as corn, cassava, sugarcane, sugar beet, and red seaweed, making it a 
desirable alternative fuel. It can contribute to the reduction in greenhouse gases from energy conversion systems [4]. One of the extensively utilized methods in this regard is to blend gasoline with ethanol, which has few drawbacks, such as the phase separation of ethanolgasoline blend [5,6]. Recently conducted researches have demonstrated that gasoline blended with midlevel hydrous ethanol makes an appropriate fuel for utilization in internal combustion engines [7]. A comparison between mid-level (0-40\% volumetric concentration of water) hydrous ethanol-gasoline blend and anhydrous gasoline-ethanol blend can be found in the research done by Schifter et al. [6]. Low NOx emission was reported using the hydrous ethanol-gasoline blends compared to the anhydrous ethanol-gasoline blend. Other studies have confirmed low NOx emissions for 60:40 gasoline-ethanol-10\% hydrous (E40h) compared to 60:40 gasoline-anhydrous ethanol (E40) [8]. The aforementioned results indicate that the water content of hydrous ethanol lowers the peak temperature and slows the combustion rate, resulting in reduced NOx emissions. The performance and emissions of a blend of water-ethanol (containing $96.2 \%$ ethanol) have been compared with those of gasoline; higher NOx emission was reported for hydrous ethanol [9]. This was attributed to a faster flame speed, which produced a higher peak pressure and, therefore, a higher peak temperature in the combustion process. However, there are some discrepancies in the literature on the effect of ethanol on NOx emissions of SI engines [10], and there are a number of other studies that have demonstrated a reduction in NOx emissions using ethanol gasoline blends [11-14]. This has been attributed to high heat of vaporization of ethanol compared to gasoline, which decreases the charge temperature and reduces thermal NOx formation [15].

\subsection{Motivation and related works}

The concept of oxygen enrichment of the intake air as a method of enhancing combustion in engines has been investigated for a long time $[16,17]$. One method to control the oxygen concentration is to inject the pure oxygen from a gas cylinder into the intake of the engine. Recently, with progress in materials science, the application of permeable membrane to separate air (separate oxygen from nitrogen in the intake air) and get oxygen-enriched intake for engine has been taken into consideration as an alternative approach. The polymer membranes with selectivity and permeability can produce higher oxygen concentrations in the intake air [18]. By means of membrane separation technology, up to $35 \%$ oxygen concentration in the intake air can be achieved and is reported in the literature [19]. By development of practical applications for oxygenenriching membranes, the results of this paper can be employed in conventional SI engines.
An effective method that can be employed to reduce the overall fuel consumption is the oxygen enrichment of combustion air, which cuts the amount of nitrogen in the flue gas, hence reducing the heat loss through the exhaust gas [20]. On the other hand, the oxygen enrichment of the intake air leads to a leaner combustion, which increases the amount of nitrogen oxides in the exhaust gas [21]. However, water content of ethanol could be employed to effectively counteract the impact of OEC on NOx emissions [22]. It seems that the enrichment of oxygen along with some other parameters (e.g., water content of ethanol, and hydrous ethanol injection rate) could be regulated in such a controlled way that the desired engine output parameters are obtained; this is the main focus of this study. This study aims to balance these opposing effects, and find an optimum condition of engine operation with improved performance and reduced emissions. Firstly, the effect of oxygen enrichment and different flow rates of hydrous ethanol on engine performance (BSFC, BMEP, fuel conversion efficiency, volumetric efficiency, relative air to fuel ratio, brake output torque, and combustion efficiency) and emission ( $\mathrm{CO}, \mathrm{CO}_{2}, \mathrm{NOx}$, and $\mathrm{HC}$ ) is investigated in this study. Secondly, the optimum values of oxygen concentration, volumetric concentration of ethanol in the ethanol-water blend, and its flow rate are found to minimize the $\mathrm{NOx}$ and CO emissions and the BSFC. The optimization algorithm we have used is a swarm intelligence based one, namely, ABC algorithm, which requires numerous sample data from the system. Therefore, an ANN is utilized as a virtual model for the engine to provide the optimization process with an estimate of engine performance and emissions parameters. Related studies that have used ANN to predict engine performance and exhaust emissions include studying the performance and exhaust emissions of a diesel engine [23]; developing correlation among torque, brake power, BSFC, volumetric efficiency, and exhaust emissions [24]; and predicting the engine brake power, torque, and the exhaust emissions [25]. Other related works include those that have focused on the use of optimization methods in engine improvement [26-28]. In this regard, Kesgin has employed the Genetic Algorithm (GA) and neural networks to predict the effects of design and operational parameters on engine efficiency and $\mathrm{NOx}$ emissions of a natural gas engine [26].

\subsection{Study procedure}

The overall flowchart of this study is depicted in Figure 1. The process started by defining the design space and the range of inputs. Then, a representative data set (including 16 distinct cases) was produced, using which the outputs were obtained experimentally for each case. Then, different training algorithms and network architectures were compared to find the most 


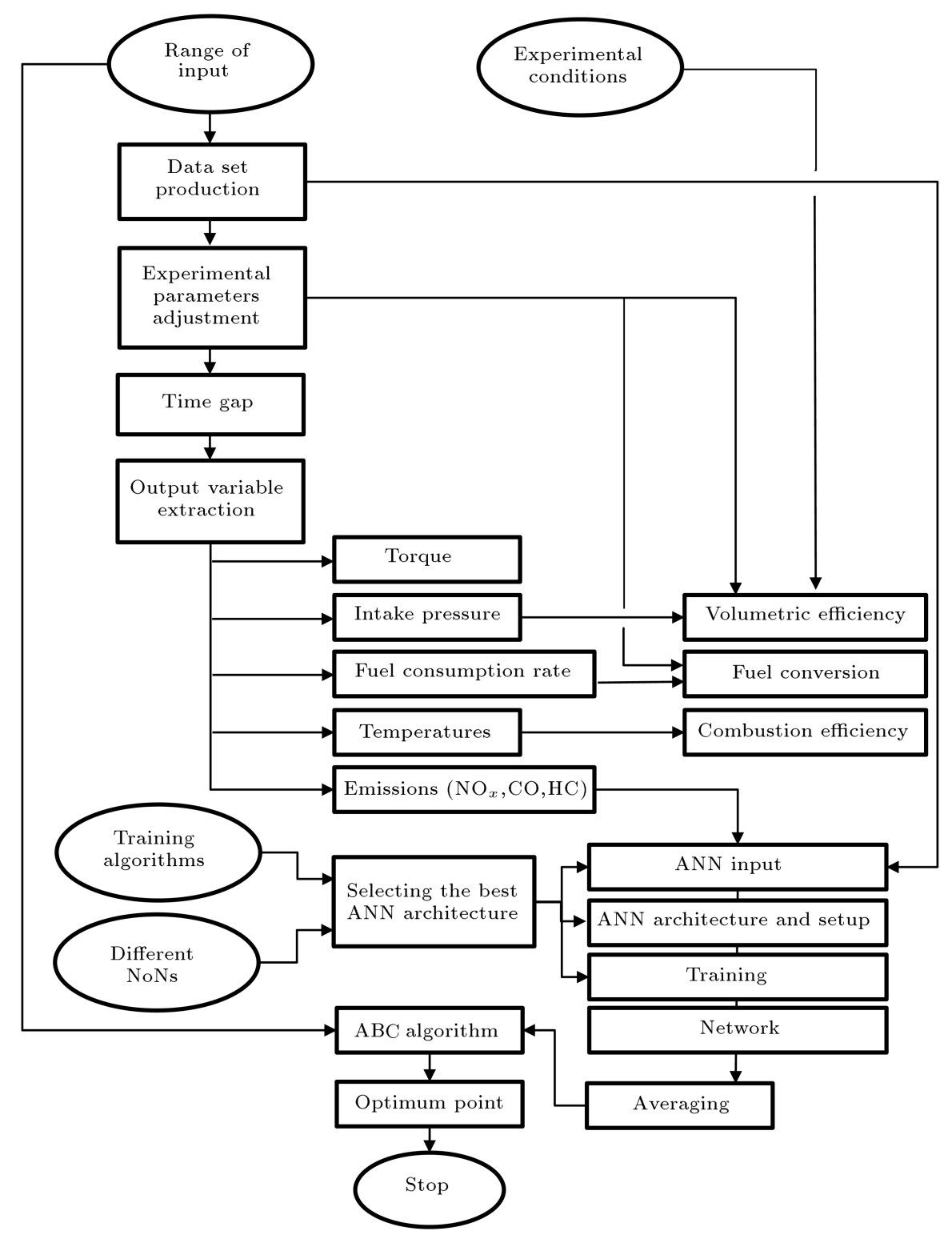

Figure 1. Overall flowchart of study procedure.

appropriate one to model the behavior of the tested engine. Thereafter, the experimental data were used to train the selected ANN, which was employed by the $\mathrm{ABC}$ algorithm to obtain the required data for the optimization process. Finally, the optimum operation condition was obtained.

\section{Experimentation}

\subsection{The experimental setup}

A KIA four-cylinder, four-stroke, naturally aspirated, SOHC engine with displacement volume of $1323 \mathrm{cc}$ was taken as the case study. Tables 1 and 2 list the general specifications of the engine and the fuel properties, respectively. Torque measurements were done by means of a $200 \mathrm{~kW}$ Schenk-WT eddy-current dynamometer. Thermocouples were used to obtain the
Table 1. General specifications of the tested engine.

\begin{tabular}{ll}
\hline Engine type & 4-cylinder, in-line, 8-valve \\
Displacement volume $(\mathrm{cc})$ & 1323 \\
Bore $\times$ stroke $(\mathrm{mm})$ & $71 \times 83.6$ \\
Valve mechanism & $\mathrm{SOHC}$ \\
Compression ratio & $9.7: 1$ \\
Combustion order & $1-3-4-2$ \\
Maximum torque $(\mathrm{Nm} / \mathrm{rpm})$ & $120 / 3000$ \\
Maximum power $(\mathrm{kW} / \mathrm{rpm})$ & $47 / 5500$ \\
Maximum speed $(\mathrm{rpm})$ & 6000 \\
\hline
\end{tabular}

inlet and outlet cooling water temperatures as well as the temperatures of oil and exhaust gases. The oil pressure was also measured using a pressure probe. The fuel consumption was determined using a laser 


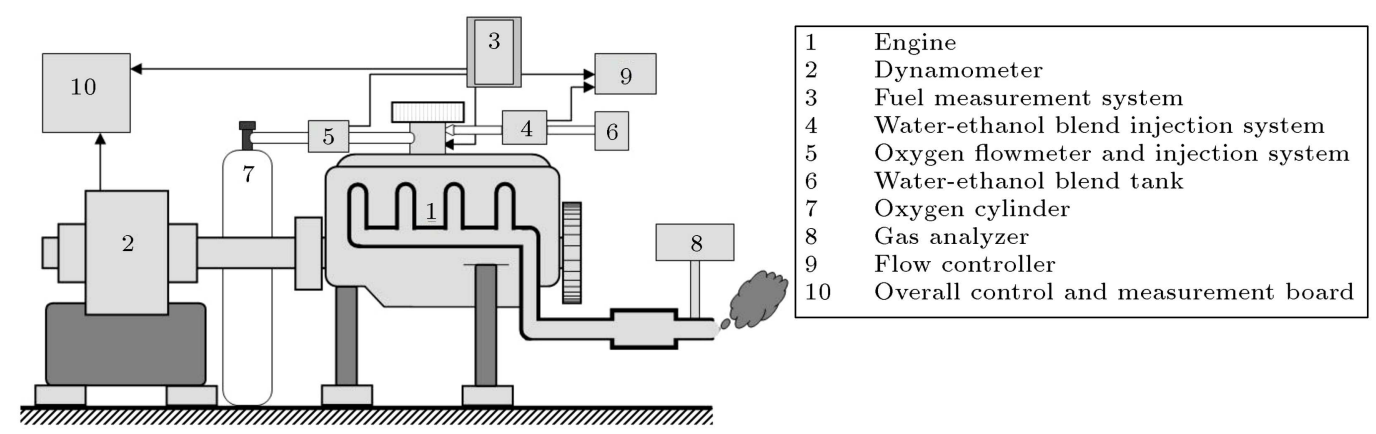

Figure 2. Schematic diagram of the experimental setup.

Table 2. Gasoline and ethanol characteristics.

\begin{tabular}{lcc}
\hline \multicolumn{1}{c}{ Fuel property } & Gasoline & Ethanol \\
\hline Density $\left(\mathrm{kg} / \mathrm{m}^{3}\right)$ & 740 & 785 \\
Lower heating value $(\mathrm{MJ} / \mathrm{kg})$ & 41.86 & 25.12 \\
Research octane number & 85.3 & 108.6 \\
Stoichiometric air-to-fuel ratio & 14.7 & 9 \\
Specific heat $(\mathrm{kJ} / \mathrm{kg} \mathrm{K})$ & 1.98 & 2.42 \\
\hline
\end{tabular}

flow meter, and the intake air flow was measured by a Venturi-type flow meter. The schematic of the experimental setup is demonstrated in Figure 2. Post catalyst gas species $\left(\mathrm{O}_{2}, \mathrm{CO}, \mathrm{CO}_{2}, \mathrm{NO}, \mathrm{NOx}, \mathrm{HC}\right)$ and stoichiometric ratio were measured using a KIMO KIGAZ 300 STD combustion gas analyzer.

In this study, the intake oxygen concentration was increased by introducing pure oxygen from an oxygen cylinder into the intake of the engine to provide sustained and stable oxygen gas. Two injection systems were designed and utilized in order to homogenously inject the hydrous ethanol and oxygen into the intake port at specified flow rates. The ignition timing was kept constant at each speed and load point, and the engine speed was constant throughout each series of experiment (at 2000 and $3000 \mathrm{rpm}$ ). In addition, the closed loop air fuel ratio was not used to allow the air fuel ratio to change by implementing OEC and hydrous ethanol injection.

\subsection{Measurement procedure}

In the first step, the performance and emission characteristics of the engine were extracted using a standard E0 gasoline fuel. Thereafter, series of experiments were performed for different conditions of input parameters including ethanol concentrations in the water-ethanol blend, hydrousethanol flow rate, and oxygen flow rates. The experiments were designed based on a BoxBehnken sampling algorithm [29]; these conditions are listed in Table 3. The upper limits for levels of oxygen, water, and ethanol mass flow rates were set by considering the stable operation of the engine; operating the engine with higher levels caused unstable combustion and, in some cases, engine stall under WOT condition. All of the experiments were performed for two different speeds (i.e., 2000 and $3000 \mathrm{rpm}$ ) at WOT. In each case, the injection systems were set to the desired points and the engine was run for a sufficient time to consume the remaining fuel of the previous case and reach steady state operation. Afterwards, variables such as the output torque, cooling water, oil and exhaust gas temperatures, fuel consumption rate, oil and intake air pressures, and the concentration of exhaust species were recorded.

\subsection{Uncertainty analysis}

A first-order uncertainty analysis was performed using the constant odds combination method, based on a 95\% confidence level, as described by Moffat [30]. Uncertainty of each measured parameter was calculated based on the instrument characteristics and the measurement dispersion. The uncertainty of each measured variable in each case of experiment is depicted in the error bars of output parameters.

\section{Artificial neural network}

The ANN is an effective method for the prediction of a system's behavior based on the experimental data. The performance of the ANN-based predictions is evaluated by the regression analysis of the network outputs (predicted parameters) and the experimental

Table 3. Input parameters in each experimental case.

\begin{tabular}{|c|c|c|c|c|c|c|c|c|c|c|c|c|c|c|c|c|}
\hline & \multicolumn{16}{|c|}{ Case } \\
\hline & 1 & 2 & 3 & 4 & 5 & 6 & 7 & 8 & 9 & 10 & 11 & 12 & 13 & 14 & 15 & 16 \\
\hline Oxygen (ml/s) & 0 & 157.3 & 368.25 & 562.3 & 0 & 0 & 0 & 0 & 157.3 & 157.3 & 368.25 & 368.25 & 562.3 & 562.3 & 368.25 & 368.25 \\
\hline Ethanol $(\mathrm{ml} / \mathrm{s})$ & 0 & 0 & 0 & 0 & 0 & 0 & 0.1837 & 0.3 & 0 & 0 & 0 & 0 & 0 & 0 & 0.1837 & 0.3 \\
\hline Water $(\mathrm{ml} / \mathrm{s})$ & 0 & 0 & 0 & 0 & 0.612 & 1 & 0.4286 & 0.7 & 0.612 & 1 & 0.612 & 1 & 0.612 & 1 & 0.4286 & 0.7 \\
\hline
\end{tabular}


values [31,32]. The criterion for performance evaluation of the ANN is the absolute fraction of variance, which is:

$$
R^{2}=1-\left(\frac{\sum_{j=1}^{N_{s}}\left(a_{j}-\mathrm{PO}_{j}\right)^{2}}{\sum_{j=1}^{N_{s}}\left(a_{j}\right)^{2}}\right),
$$

Mean Error Percentage (MEP):

$$
\operatorname{MEP}(\%)=\frac{1}{N_{s}} \sum_{j=1}^{N_{s}}\left|100 \times \frac{\left(a_{j}-\mathrm{PO}_{j}\right)}{a_{j}}\right|,
$$

and the Root Mean Square Error (RMSE):

$$
\mathrm{RMSE}=\sqrt{\frac{\sum_{j=1}^{N_{s}}\left(a_{j}-\mathrm{PO}_{j}\right)^{2}}{N_{s}},}
$$

where $a$ is the actual output, PO the predicted output, and $N_{s}$ the number of points in the data set [31,32].

In this study, an ANN model was employed to establish a correlation between the input parameters and the engine performance and emissions as the output parameters. The general architecture of the ANN is a multi-layer perceptron with one hidden layer demonstrated in Figure 3. Inputs include intake air oxygen concentration, hydrous ethanol flow rate, and the ethanol concentration in the blend. Outputs of the ANN are NOx and CO concentrations in exhaust gases and $\eta_{f}$.

Feed-forward back-propagation algorithm was used in conjunction with a hyperbolic tangent sigmoid (tansig) activation function for the hidden layer and a linear (purelin) function for the output layer in the ANN development process [3]. Four distinct learning algorithms including the trainbfg, trainscg, trainlm, and trainrp with NoN in the range of 10 to 28 neurons [23] were used and compared to select the most accurate configuration of the ANN. From the whole set of experimental data, $70 \%$ were set aside for training, $15 \%$ for validation, and $15 \%$ for testing during the ANN development and optimization.

\section{Optimization}

In order to obtain the optimum input parameters of the engine, an optimization algorithm (ABC algorithm) was employed to minimize the following objective function:

$$
\mathrm{OF}=K_{E} \eta_{F}+K_{N} E_{\mathrm{NO}_{x}}+K_{C} E_{\mathrm{CO}}
$$

where $K_{E}, K_{N}$, and $K_{C}$ are weights corresponding to the fuel conversion efficiency, NOx emission, and $\mathrm{CO}$ emission, respectively, and the search space can be defined in terms of the input parameters. The only constraints of the optimization problem are the physical input limitations. The Artificial Bee Colony (ABC) algorithm, which has been used in this study, is a swarm intelligence-based algorithm that has shown an acceptable performance in terms of reliability, accuracy, and convergence speed $[33,34]$. The $\mathrm{ABC}$ has an iterative behavior, so it needs to evaluate the output of the engine repeatedly. We used ANN as a meta model to provide $\mathrm{ABC}$ with the required data. Each time the $\mathrm{ABC}$ needed to acquire data from ANN, the network was run fifty times and the outputs average was considered as the input to the $\mathrm{ABC}$; it guaranteed the accuracy and reliability of the network output.

\section{Results and discussion}

\subsection{Performance and emission characteristics}

\subsubsection{Brake torque}

Figure 4 indicates the brake torque for each experimental case at $2000 \mathrm{rpm}$ (mid-range speed of the engine) and $3000 \mathrm{rpm}$ (the speed of maximum torque output). The results demonstrate that an increase in the oxygen flow rate leads to a considerable increase in the output torque. The increase in the output torque can be attributed to the increase in oxygen percentage in the intake charge, which raises the average temperature and the mean effective pressure in the combustion chamber. Furthermore, it is observed that the water content in the hydrous ethanol leads to a decrease in brake torque, which can be attributed to diminished IMEP as a result of reduced flame temperature and

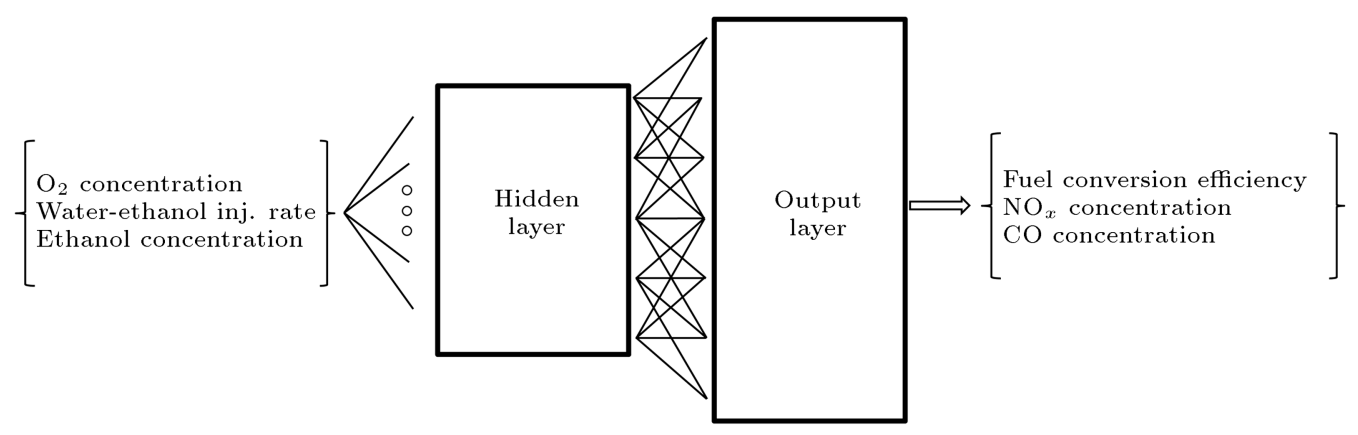

Figure 3. The general architecture of the ANN. 


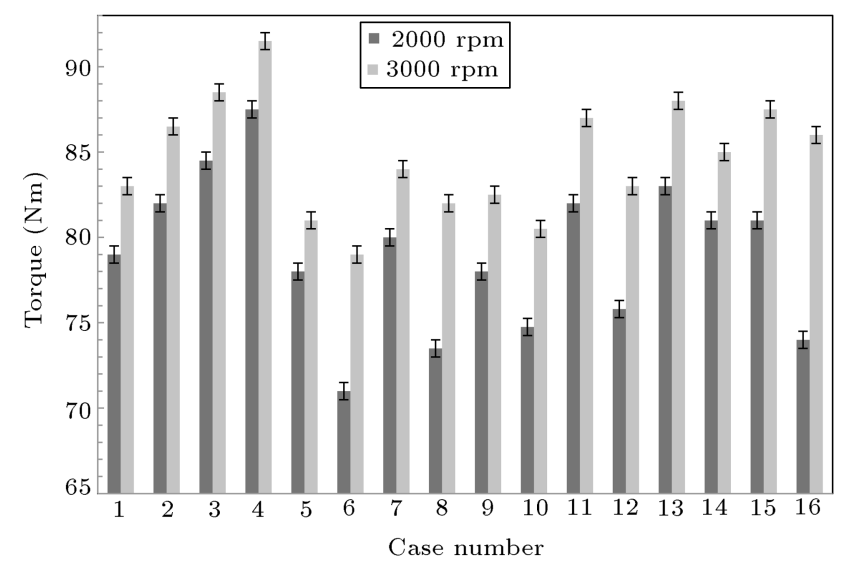

Figure 4. Measured output torque and the corresponding error bar.

lower flame propagation speed that necessitates an advance in spark timing to achieve the maximum torque. It should be mentioned that this observation is mainly due to the operation under constant ignition timing at each rpm and load point, not necessarily the optimal ignition timing for the case of water injection.

Ethanol has a higher heat of evaporation than gasoline has; this provides cooler and denser fuel-air intake charge, and thus a higher output torque is produced [35]. It also increases the knock resistance of the air-fuel mixture. The outcome is equivalent to having a fuel with a higher octane number, which will support much larger compression ratios before the onset of ignition [36-40]. When the engine is operated in knock limited conditions, both water and ethanol can suppress knock and enable the engine to run with optimal ignition timing to achieve the maximum torque and BTE [41].

\subsubsection{Fuel conversion efficiency and $B S F C$}

The fuel conversion efficiency can be calculated by Eq. (5), which demonstrates the ratio of the work produced per cycle to the amount of fuel energy supplied per cycle that can be released in the combustion process [42]:

$$
\eta_{F}=\frac{P}{\dot{m}_{f} Q_{\mathrm{HV}}} .
$$

Figure 5 shows the fuel conversion efficiency for each experimental case at engine speeds of 2000 and $3000 \mathrm{rpm}$. The results indicate that with increase in the intake air oxygen content, the thermal efficiency increases and, consequently, the BSFC diminishes according to Eq. (6):

$$
\mathrm{BSFC}=\frac{\dot{m}_{f}}{P} \text {. }
$$

Since the air fuel ratio was not closed-loop controlled, oxygen enrichment led to a leaner and more complete combustion with higher values of relative air-tofuel ratio $(\lambda)$. Furthermore, the oxygen enrichment

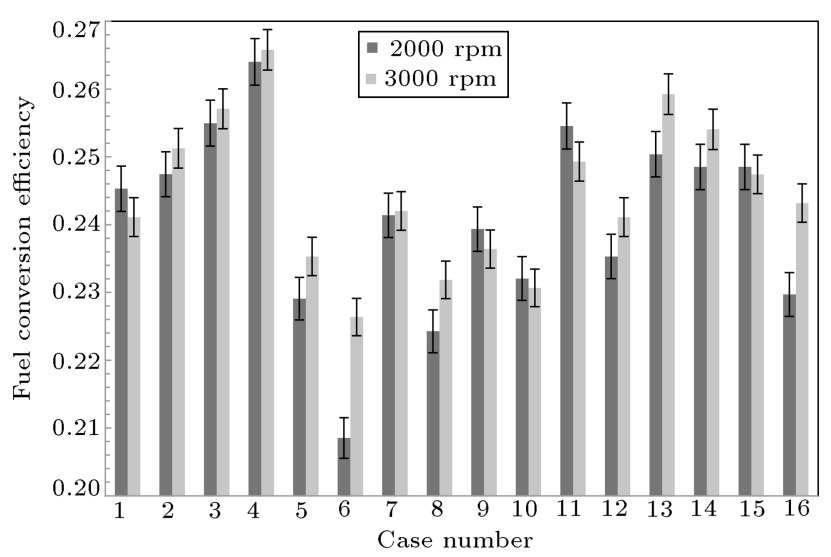

Figure 5. Fuel conversion efficiencies in each experimental case.

reduced the amount of nitrogen in the exhaust gas, which contributed to lower thermal losses through the exhaust [20]. On the other hand, it was observed that an increase in the oxygen content resulted in a higher temperature difference between the outlet and inlet cooling waters. This observation was a result of a higher adiabatic flame temperature of oxygen enriched combustion, which increased the amount of heat flux to cylinder walls. The value of fuel conversion efficiency is obtained through a balance between the abovementioned factors.

It was observed that the thermal efficiency had an increasing trend as the ethanol content increased. Since ethanol had a higher flame speed and lower combustion temperature, it reduced the amount of heat loss to cylinder walls and, thus, enhanced the thermal efficiency [9]. Another effect was caused by the vaporization of fuel, which continued during the compression stroke. This had two opposing effects; first, decrease in the temperature of the working charge, which reduced the compression work, and, second, increase in the volume charge, which increased the compression work. The heat of vaporization of ethanol is higher than that of gasoline, which increases the cooling effect and reduces the compression work and, hence, enhances the brake thermal efficiency [43].

Water content has shown to have a reducing effect on thermal efficiency. It was observed that water reduced the flame temperature and, hence, the heat flux to cylinder walls. In addition, water absorbed the heat and lowered the pressure as the charge was compressed, thereby reducing the work of the compression stroke [44]. However, thermal loss through exhaust gases increases significantly due to the vapor content of these gases. In addition, water reduces the flame speed, which necessitates a change in ignition timing to optimal combustion phasing and maximum BTE $[45,46]$. Since the ignition timing was fixed at each rpm in this work, the combustion phasing was not optimum for the case of water injection. 


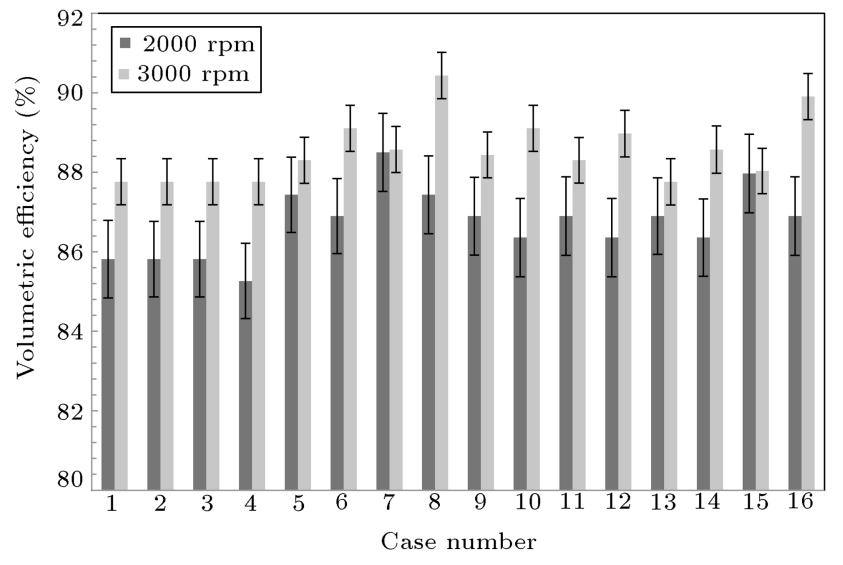

Figure 6. Volumetric efficiencies according to Relation (7).

\subsubsection{Volumetric efficiency}

The volumetric efficiency for the test engine is calculated by:

$$
\eta_{v}=\frac{2 \dot{m}_{a}}{\rho_{a, i} V_{d} N}
$$

where $\dot{m}_{a}$ is the mass flow rate of air induced into the cylinder, which is calculated using:

$$
\dot{m}_{a}=\frac{A_{E} p_{0}}{\sqrt{R T_{0}}}\left\{\frac{2 \gamma}{\gamma-1}\left[\left(\frac{p}{p_{0}}\right)^{\frac{2}{\gamma}}-\left(\frac{p}{p_{0}}\right)^{\frac{(\gamma+1)}{\gamma}}\right]\right\}^{1 / 2}
$$

The effect of different input parameters on the volumetric efficiency is depicted in Figure 6. It is shown that the injection of hydrous ethanol results in a lower fuel-air mixture temperature in the intake manifold due to the evaporation of water and ethanol. This increases the charge density and, therefore, the volumetric efficiency. The volumetric efficiencies for Cases 1, 5, and 7 at $2000 \mathrm{rpm}$ were $85.8 \%, 87.44 \%$, and $88.50 \%$, respectively. The oxygen enrichment did not show any considerable effect on volumetric efficiency.

\subsubsection{Combustion efficiency}

The combustion efficiency is calculated by Eq. (9):

$$
\eta_{v}=\frac{\dot{m}_{a}\left(\sum_{i, \text { Reactants }} n_{i} \Delta \bar{h}_{f, i}^{0}-\sum_{i, \text { Products }} n_{i} \Delta \bar{h}_{f, i}^{0}\right)}{\dot{m}_{f} Q_{\mathrm{HV}}}
$$

The combustion efficiency is calculated for each case and depicted in Figure 7. For cases in which ethanol is injected, its heating value is added to the denominator of Eq. (9). It is observed that with oxygen enrichment, the combustion efficiency increases, mainly because of a leaner and more complete combustion [40]. For instance, at $2000 \mathrm{rpm}$, the combustion efficiency in

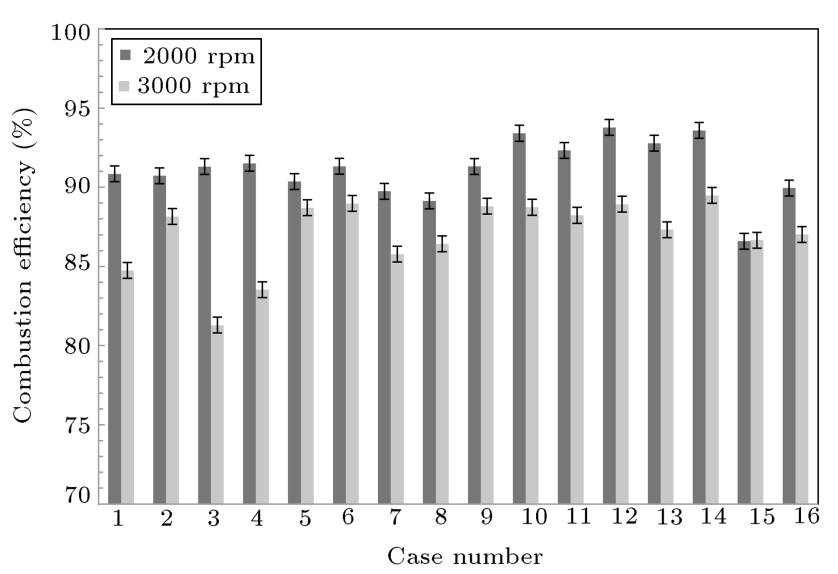

Figure 7. Combustion efficiency of all cases according to Relation (9).

Case 1 is $90.85 \%$, and through a mid-level oxygen enrichment in Case 3, the combustion efficiency increases to $91.31 \%$. However, the use of oxygen enrichment in some cases results in a lower value of combustion efficiency, as observed in Case 2 with a combustion efficiency of $90.73 \%$. This is due to a higher flame temperature and, thus, a higher fraction of CO, which is considered as a partly burnt fuel in the exhaust gas.

It was observed that water injection could be effectively utilized to counteract the temperature increasing effect of oxygen. The best values of combustion efficiency were obtained in Case $12(93.78 \%)$ and Case $14(93.59 \%)$ in which both water and oxygen were injected.

In this study, the AF ratio was not closed-loop controlled; therefore, injection of ethanol into the intake air led to a richer charge, which increased the amount of unburnt or partially oxidized $\mathrm{HC}$ and diminished the combustion efficiency. For instance, combustion efficiencies of $89.75 \%$ and $89.13 \%$ were obtained in Cases 7 and 8, respectively. Contrary to these results, when a closed-loop control system is employed to maintain stoichiometric combustion, the use of ethanol as an oxygenated fuel is expected to improve the combustion efficiency [47].

\subsubsection{NOx emissions}

Figure 8 depicts NOx emissions in different experimental cases. The water content in the water-ethanol blend lowers the peak temperature, thereby reducing the NOx emissions [37]. Cases 5 and 6 (which have water injection) indicate relative reductions of $10.4 \%$ and $25.3 \%$ in NOx emissions, respectively. The ethanol content itself demonstrated a decrease in NOx emission; this observation is consistent with some of the previous studies [10-14] and is primarily due to high heat of vaporization of ethanol compared to gasoline, which decreases the charge temperature [15].

The injection of oxygen results in an oxygen enriched combustion, which increases the peak tem- 


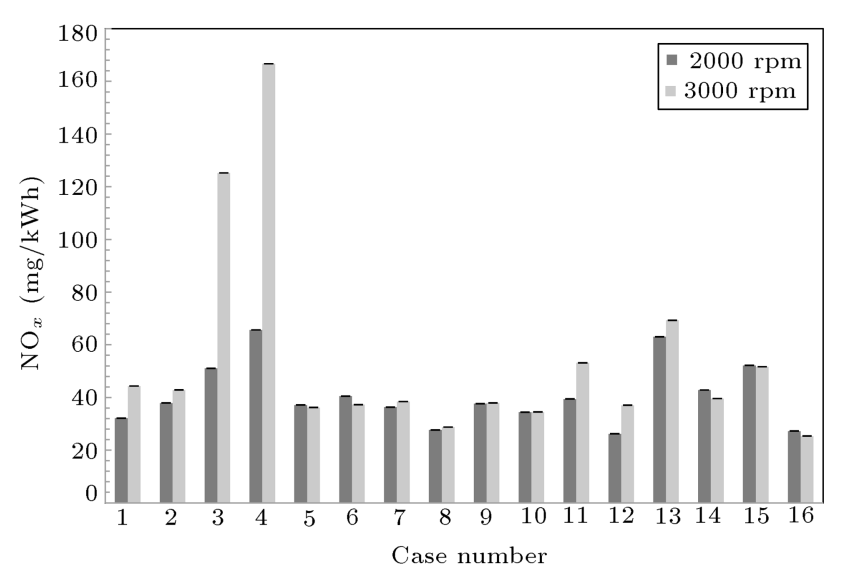

Figure 8. Brake specific NOx emissions.

perature and $\lambda$, thereby increasing the NOx formation in the combustion chamber [21]. Cases 2, 3, and 4 demonstrate $18.5 \%, 63.8 \%$, and $117.4 \%$ increases in NOx emissions, respectively, at $2000 \mathrm{rpm}$.

\subsubsection{CO emission}

The most influential parameter on $\mathrm{CO}$ emission is the relative air-fuel ratio [35]. As indicated in Figure 9, which illustrates the $\mathrm{CO}$ emissions in each case, the addition of oxygen mostly has reducing effect on CO concentrations; yet, some cases exhibit slightly increased $\mathrm{CO}$ values. Oxygen injection makes the combustion leaner; thus, a lower $\mathrm{CO}$ concentration is expected. On the other hand, it raises the flame temperature, which increases the equilibrium concentration of CO [48]. By comparing Cases 2, 3, and 4 (at $2000 \mathrm{rpm}$ ), with respective $\mathrm{CO}$ concentrations of $2.08 \%, 1.88 \%$, and $1.79 \%$, it is obvious that the increase in the oxygen injection rate reduces the $\mathrm{CO}$ emission.

Water injection mostly lowers the CO emission, for it leads to lower flame temperatures. On the other hand, the addition of hydrous ethanol increases the $\mathrm{CO}$ concentrations, since it contributes to a lower $\lambda$. Cases 7 and 8 have CO concentrations of $2.31 \%$ and $2.45 \%$, respectively, which demonstrates $11.6 \%$

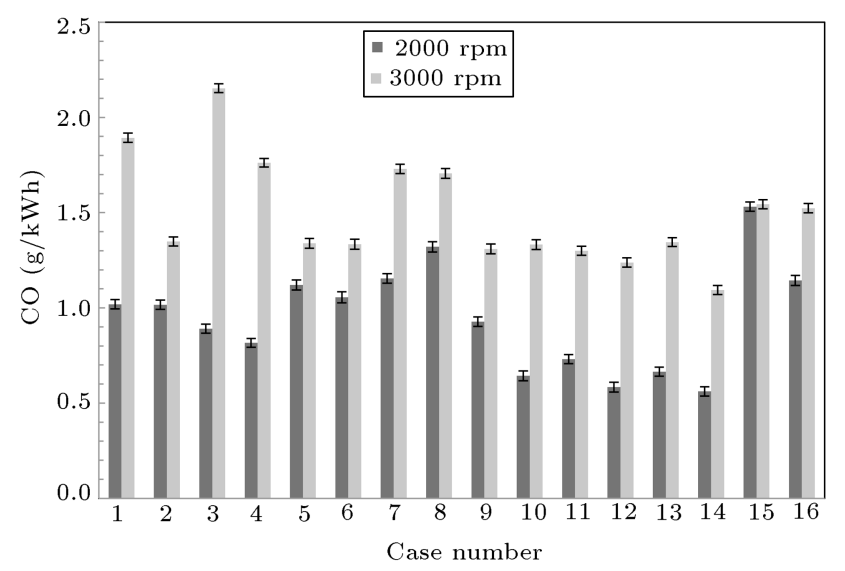

Figure 9. Brake specific $\mathrm{CO}$ emission.

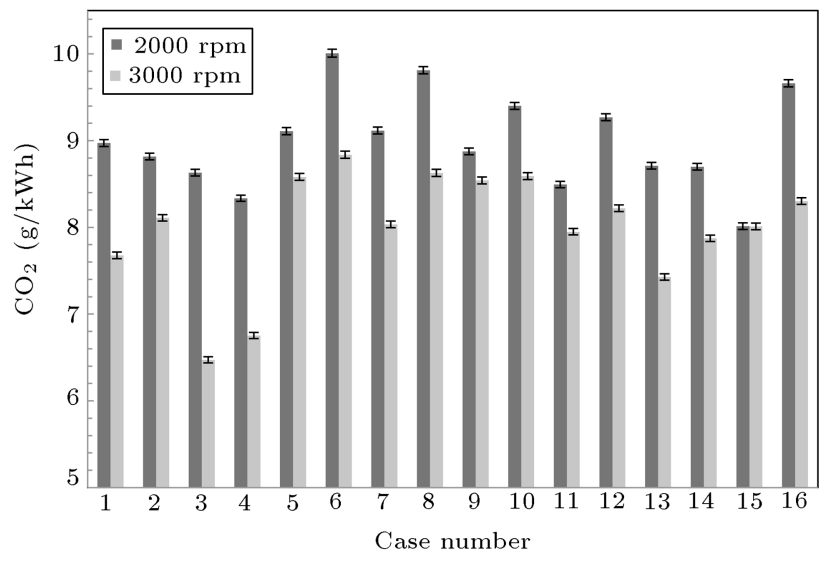

Figure 10. Brake specific $\mathrm{CO}_{2}$ emission.

and $18.4 \%$ increase with respect to standard operation condition (Case 1).

\subsection{7. $\mathrm{CO}_{2}$ emission}

The amount of $\mathrm{CO}_{2}$ mainly depends on the air-to-fuel ratio and the formation of $\mathrm{CO}[35,49]$. $\mathrm{CO}_{2}$ concentration for each case has been depicted in Figure 10. It was observed that oxygen injection had both increasing and decreasing effects on $\mathrm{CO}_{2}$ concentration in different situations. The addition of oxygen makes a leaner and more complete combustion, which should increase the $\mathrm{CO}_{2}$ concentration. On the other hand, it leads to higher flame temperatures, which would increase the $\mathrm{CO}$ concentration and, consequently, lower the amount of $\mathrm{CO}_{2}$. Thus, $\mathrm{CO}_{2}$ concentration is a compromise between the abovementioned factors. In some cases, where only oxygen was injected, it was observed that $\mathrm{CO}_{2}$ concentration chiefly decreased. For instance, Case 2 had a $\mathrm{CO}_{2}$ emission of $11.5 \%$, which was less than the $11.6 \% \mathrm{CO}_{2}$ concentration in Case 1 . On the other hand, in cases in which the flame temperature is reduced by water injection, oxygen injection increases the $\mathrm{CO}_{2}$ emission, like in Cases 5, 9, and 11, with $11 \%$, $11.2 \%$, and $11.4 \%$ concentrations of $\mathrm{CO}_{2}$, respectively.

Water injection alone has a decreasing effect on $\mathrm{CO}_{2}$ concentration. Although it reduces the flame temperature and shifts the equilibrium in favor of $\mathrm{CO}_{2}$, water vapor dilutes the exhaust gases and, hence, reduces the volumetric concentration of $\mathrm{CO}_{2}$.

The injection of hydrous ethanol resulted in high $\mathrm{CO}_{2}$ concentrations in comparison with pure water injection. This was demonstrated by Cases 5 and 7 , with $11 \%$ and $11.6 \% \mathrm{CO}_{2}$ concentrations, respectively.

\subsubsection{Relative air-to-fuel ratio $(\lambda)$}

Figure 11 illustrates $\lambda$ in each case. The cases with oxygen enrichment had a relatively leaner combustion; for instance, the values of $\lambda$ in Cases 2, 3, and 4 were $1.01,1.05$, and 1.09, respectively. On the other hand, the ethanol content in cases with hydrous ethanol injection resulted in a richer combustion, because no 


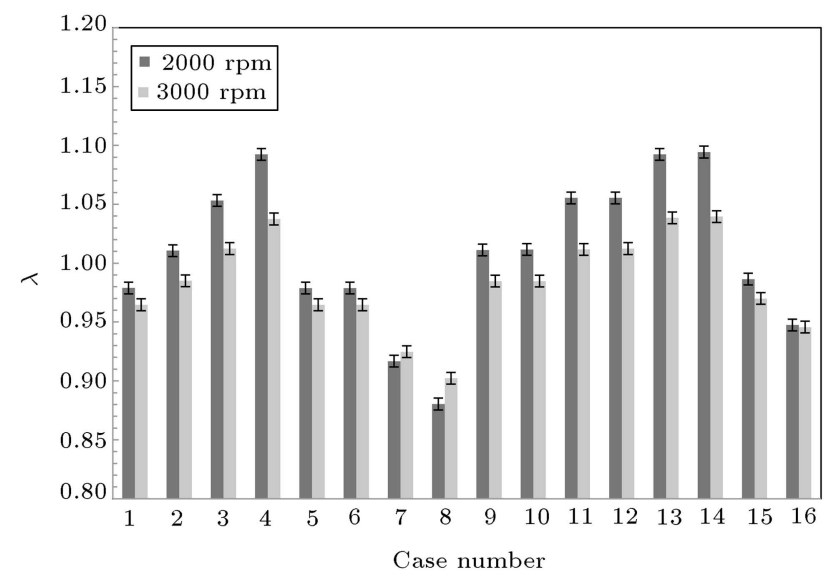

Figure 11. Relative air-to-fuel ratio.

feedback was provided for fuel system of the engine in these cases. The values of $\lambda$ in Cases 7 and 8 were 0.92 and 0.88 , respectively.

\subsection{ANN training and optimization results}

As can be seen in Table 4, different training algorithms with different numbers of neurons (as discussed in Section 3) were evaluated based on three criteria (i.e., Eqs. (1)-(3)). The results showed that the training algorithm trainlm with 24 neurons in hidden layer had the best performance. Thus, it was chosen as the engine model to be used in the optimization process. The priority of each input parameter in the cost function (Eq. (4)) could be determined by changing the corresponding constants $K_{E}, K_{N}$, and $K_{C}$. As it was discussed in the previous sections, reducing the exhaust emissions results in reduction in $\eta_{f}$. Here, the mentioned constants were selected in a way that no more than $2 \%$ reduction in $\eta_{f}$ was allowed to obtain reduced exhaust emissions. Then, we chose:

$$
K_{E}=-800, \quad K_{N}=8, \quad K_{C}=2 .
$$

Then, the optimization process was run for the input parameters within the ranges listed in Table 5 .

The results are tabulated in Table 6 ; optimization results and experiments indicate that at the maximum torque speed (i.e., $3000 \mathrm{rpm}$ in this case), both the performance and emissions, are improved, while at a mid-range speed, i.e. $2000 \mathrm{rpm}$, the performance and $\mathrm{CO}$ emission are improved at the expense of slightly increased NOx emissions.

\section{Conclusion}

The main objective of this study was to demonstrate the potential of Artificial Neural Networks as a metaheuristic model to predict the behavior of IC engines, and the use of Artificial Bee Colony as a swarm intelligence based algorithm to optimize engine performance and emissions. As a case study, oxygen enriched combustion was employed to improve the performance and emissions of an SI engine fueled with gasoline and hydrous ethanol. The engine was tested at different rates of hydrous ethanol injection in intake port, ethanol concentrations, and intake air oxygen concentrations. The engine test results demonstrated that injecting hydrous ethanol in the intake port of an SI engine led to higher volumetric efficiency,

Table 5. Range of input parameters for optimization.

\begin{tabular}{ll}
\hline \multicolumn{1}{c}{ Parameter } & \multicolumn{1}{c}{ Range } \\
\hline Hydrous ethanol flow rate $\left(\dot{m}_{\mathrm{HE}}\right)$ & $0-1.3 \mathrm{ml} / \mathrm{s}$ \\
Ethanol concentration in & $0-30 \%$ \\
the hydrous ethanol $\left(C_{E}\right)$ & \\
Intake air oxygen concentration $\left(C_{\mathrm{O}_{2}}\right)$ & $21-24.25 \%$ \\
\hline
\end{tabular}

Table 4. Different ANN setups and training algorithms.

\begin{tabular}{|c|c|c|c|c|c|c|c|c|c|c|c|c|}
\hline \multirow[b]{3}{*}{ NoN } & \multicolumn{12}{|c|}{$\begin{array}{l}\text { Learning } \\
\text { algorithm }\end{array}$} \\
\hline & \multicolumn{3}{|c|}{ trainlm } & \multicolumn{3}{|c|}{ trainrp } & \multicolumn{3}{|c|}{ trainscg } & \multicolumn{3}{|c|}{ trainbfg } \\
\hline & $R^{2}$ & $\begin{array}{c}\text { MEP } \\
(\%)\end{array}$ & RMSE & $R^{2}$ & $\begin{array}{c}\text { MEP } \\
(\%)\end{array}$ & RMSE & $R^{2}$ & $\begin{array}{c}\text { MEP } \\
(\%)\end{array}$ & RMSE & $R^{2}$ & $\begin{array}{c}\text { MEP } \\
(\%)\end{array}$ & RMSE \\
\hline 10 & 0.9839 & 3.6976 & 27.9901 & 0.9619 & 9.9328 & 66.4089 & 0.9758 & 16.1983 & 58.3485 & 0.9499 & 15.3753 & 60.49 \\
\hline 12 & 0.9909 & 1.9962 & 18.4177 & 0.9736 & 9.592 & 57.2892 & 0.9749 & 15.781 & 54.8397 & 0.9315 & 17.9094 & 78.2368 \\
\hline 14 & 0.9854 & 3.523 & 27.8613 & 0.9628 & 10.8818 & 63.5825 & 0.9838 & 15.2527 & 43.8606 & 0.9537 & 16.39 & 58.5733 \\
\hline 16 & 0.9886 & 2.5121 & 26.1302 & 0.9798 & 9.0384 & 50.2893 & 0.9620 & 15.9552 & 51.738 & 0.9806 & 14.7625 & 42.632 \\
\hline 18 & 0.9905 & 1.7666 & 22.7058 & 0.9576 & 10.1759 & 57.8719 & 0.9811 & 16.2088 & 48.384 & 0.9699 & 16.454 & 54.141 \\
\hline 20 & 0.9903 & 2.4607 & 24.0985 & 0.9703 & 9.6016 & 55.8838 & 0.9733 & 16.3098 & 48.8909 & 0.9800 & 16.1211 & 45.8868 \\
\hline 22 & 0.9917 & 2.2028 & 24.6576 & & & & & & & & & \\
\hline 24 & 0.9949 & 1.709 & 18.7293 & & & & & & & & & \\
\hline 26 & 0.9933 & 1.7598 & 20.3856 & & & & & & & & & \\
\hline 28 & 0.9484 & 3.6104 & 43.502 & & & & & & & & & \\
\hline
\end{tabular}


Table 6. Optimization results.

\begin{tabular}{lccccccc}
\hline Condition & $\boldsymbol{N}(\mathbf{r p m})$ & $\dot{\boldsymbol{m}}_{\boldsymbol{H} \boldsymbol{E}}(\mathbf{m l} / \mathbf{s})$ & $\boldsymbol{C}_{\boldsymbol{E}}(\boldsymbol{\%})$ & $\boldsymbol{C}_{\mathrm{O}_{\boldsymbol{2}}}(\boldsymbol{\%})$ & $\boldsymbol{\eta}_{\boldsymbol{f}}(\boldsymbol{\%})$ & $\mathbf{N O x}(\mathbf{p p m})$ & $\mathbf{C O}(\boldsymbol{\%})$ \\
\hline \multirow{2}{*}{ Initial } & 2000 & 0 & 0 & 0 & 24.53 & 602 & 2.07 \\
& 3000 & 0 & 0 & 0 & 24.11 & 803 & 3.83 \\
& & & & & & & \\
\multirow{2}{*}{ Optimized } & 2000 & 0.35 & 22.5 & 23.92 & 25.54 & 772 & 1.68 \\
& 3000 & 0.94 & 12.3 & 22.36 & 24.40 & 691 & 2.46 \\
\hline
\end{tabular}

slightly higher fuel conversion efficiency, higher CO, and lower NOx emissions. On the other hand, the oxygen enrichment of intake air did not affect the volumetric efficiency, substantially increased the fuel conversion efficiency and NOx emissions, and in most of cases reduced the CO. The behavior of the engine was modeled by training a meta-heuristic model (ANN) using the experimental data. This model was then used in conjunction with an optimization algorithm to optimize the engine performance and emissions simultaneously. Both the optimization and experimental results demonstrated that at the maximum torque speed, $3000 \mathrm{rpm}$ in this case, both the performance and emissions were improved, while at a mid-range speed, $2000 \mathrm{rpm}$, the performance was improved and the $\mathrm{CO}$ emission was reduced at the expense of slightly increased NOx emissions.

\section{Nomenclature}

\section{SI}

$\mathrm{ABC}$

Spark Ignition

ANN

Artificial Bee Colony

$\dot{m}_{f}$

Artificial Neural Network

OEC

Mass flow rate of fuel $(\mathrm{kg} / \mathrm{s})$

BTE

Oxygen-Enriched Combustion

BSFC

Brake Thermal Efficiency

Brake Specific Fuel Consumption (g/kWh)

$Q_{\mathrm{HV}} \quad$ Heating Value of fuel $(\mathrm{kJ} / \mathrm{kg})$

SOHC Single overhead camshaft

$P \quad$ Brake power $(\mathrm{kW})$

$\eta_{f} \quad$ Fuel conversion efficiency

$\dot{m}_{a} \quad$ Mass flow rate of air induced into the cylinder

$\rho_{a, i} \quad$ Inlet air density $\left(\mathrm{kg} / \mathrm{m}^{3}\right)$

$\eta_{v} \quad$ Volumetric efficiency

$N \quad$ Engine speed (rpm)

$V_{d} \quad$ Displacement volume of the cylinder $\left(\mathrm{m}^{3}\right)$

$\gamma\left(=\frac{c_{p}}{c_{v}}\right)$

$R$

Ratio of specific heats

Gas constant
$T_{0} \quad$ Temperature upstream of the restriction

$p^{0} \quad$ Total pressure upstream of the restriction

$A_{E} \quad$ Flow restriction effective area

$p \quad$ Pressure at the throat of the restriction

$\eta_{c} \quad$ Combustion efficiency

$\lambda \quad$ Relative air-to-fuel ratio

$\dot{m}_{x} \quad$ Mass flow rate of pollutant $x(\mathrm{~g} / \mathrm{s})$

$n_{i} \quad$ Number of moles of species $i$ in the reactants or products per unit mass of working fluid

$\bar{h}_{f, i} \quad$ Standard enthalpy of formation of species $i$ at ambient temperature

MEP Mean Error Percentage

RMSE Root Mean Square Error

$R^{2} \quad$ Absolute fraction of variance

$N_{s} \quad$ Number of the points in the data set

A Actual output

PO Predicted Output

NoN Number of hidden layer Neurons

trainbfg BFGS quasi-Newton back-propagation

trainscg Scaled conjugate gradient backpropagation

trainlm Levenberg-Marquardt backpropagation

Trainrp Resilient back-propagation

tansig Hyperbolic tangent sigmoid

purelin Linear

WOT Wide Open Throttle

$C_{\mathrm{O} 2} \quad$ Intake air oxygen concentration

$C_{E} \quad$ Ethanol concentration in the hydrous ethanol

$\dot{m}_{H E} \quad$ Hydrous ethanol flow rate

\section{References}

1. Çay, Y., Korkmaz, I., Çiçek, A., and Kara, F. "Prediction of engine performance and exhaust emissions for gasoline and methanol using artificial neural network", Energy, 50, pp. 177-186 (2013). 
2. Wiesenthal, T., Leduc, G., Christidis, P., Schade, B., Pelkmans, L., and Govaerts, L. "Biofuel support policies in Europe: lessons learnt for the long way ahead", Renew. Sust. Energy. Rev., 13, pp. 789-800 (2009).

3. Ismail, H.M., Ng, H.K., Queck, C.W., and Gan, S. "Artificial neural networks modelling of engineout responses for a light-duty diesel engine fuelled with biodiesel blends", Appl. Energy, 92, pp. 769-777 (2012).

4. Costagliola, M.A., De Simio, L., Iannaccone, S., and Prati, M.V. "Combustion efficiency and engine out emissions of a S.I. engine fueled with alcohol/gasoline blends", Appl. Energy, 111, pp. 162-171 (2012).

5. Chen, R.H., Chiang, L.B., Wub, M.H., and Lin, T.H. "Gasoline displacement and NOx reduction in an SI engine by aqueous alcohol injection", Fuel, 89, pp. 604610 (2010).

6. Schifter, I., Diaz, L., Gómez, J.P., and Gonzalez, U. "Combustion characterization in a single cylinder engine with mid-levels hydrated ethanol-gasoline blended fuels", Fuel, 103, pp. 292-298 (2013).

7. Al-Hasan, M. "Effect of ethanol-unleaded gasoline blends on engine performance and exhaust emission", Energy Convers. Manage., 44, pp. 1547-1561 (2003).

8. Kyriakides, A., Dimas, V., Lymperopoulou, E., Karonis, D., and Lois, E. "Evaluation of gasoline-ethanolwater ternary mixtures used as a fuel for an Otto engine", Fuel, 108, pp. 208-215 (2013).

9. Costa, R.C. and Sodré, J.R. "Hydrous ethanol vs. gasoline-ethanol blend: engine performance and emissions", Fuel, 89(2), pp. 287-293 (2010).

10. Masum, B.M., Masjuki, H.H., Kalam, M.A., Rizwanul Fattah, I.M., Palash, S.M., and Abedin, M.J. "Effect of ethanol-gasoline blend on NOx emission in SI engine", Renew. Sustain. Energy Rev., 24, pp. 209-222 (2013).

11. Tavares, J.R., Sthel, M.S., Campos, L.S., Rocha, M.V., Lima, G.R., DaSilva, M.G., and Vargas, H. "Evaluation of pollutant gases emitted by ethanol and gasoline powered vehicles", Procedia. Environ. Sci., 4, pp. 51-60 (2011).

12. Furey, R.L. and King, J.B. "Evaporative and exhaust emissions from cars fueled with gasoline containing ethanol or methyltert-butyl ether", SAE Paper, 800261 (1980).

13. Rajan, S. "Water-ethanol-gasoline blends physical properties, power, and pollution characteristics", $J$. Eng. Gas. Turb. Power, 106, pp. 841-848 (1984).

14. Rice, R.W., Sanyal, A.K., Elrod, A.C., and Bata, R.M. "Exhaust gas emissions of butanol, ethanol, and methanol-gasoline blends", J. Eng. Gas. Turb. Power, 113(3), pp. 377-381 (1991).

15. Gravalos, I., Moshou, D., Gialamas, T., Xyradakis, P., Kateris, D., and Tsiropoulos, Z. "Performance and emission characteristics of spark ignition engine fuelled with ethanol and methanol gasoline blended fuels", Alternative Fuel., Published by InTech, pp. 155-174 (2011).
16. Rigby, G.R. and Watson, H.C. "Application of membrane gas separation to oxygen enrichment of diesel engines", J. Membr. Sci., 87(1-2), pp. 159-169 (1994).

17. Song, J., Zello, V., Boehman, A.L., and Waller, F.J. "Comparison of the impact of intake oxygen enrichment and fuel oxygenation on diesel combustion and emissions", Energy Fuels, 18(5), pp. 1282-1290 (2004).

18. Kadota, T. and Yamasaki, H. "Recent advances in the combustion of water fuel emulsion", Prog. Energy Combust. Sci., 28, pp. 385-404 (2002).

19. Assanis, D.N., Poola, R.B., Sekar, R., Assanis, D.N., and Cataldi, G.R. "Study of using oxygen enriched combustion air for locomotive diesel engines", J. Eng. Gas Turb. Power, 123, pp. 157-166 (2001).

20. Bisio, G., Bosio, A., and Rubatto, G. "Thermodynamics applied to oxygen enrichment of combustion air", Energy Convers. Manage., 43, pp. 2589-2600 (2002).

21. Zhang, W., Chen, Z., Li, W., Shu, G., Xu, B., and Shen, Y. "Influence of EGR and oxygen-enriched air on diesel engine NO-smoke emission and combustion characteristic", Appl. Energy, 107, pp. 304-314 (2013).

22. Liang, Y., Shu, G., Wei, H., and Zhang, W. "Effect of oxygen enriched combustion and water-diesel emulsion on the performance and emissions of turbocharged diesel engine", Energy Convers. Manage., 73, pp. 6977 (2013).

23. Ghobadian, B., Rahimi, H., Nikbakht, A.M., Najafi, G., and Yusaf, T.F. "Diesel engine performance and exhaust emission analysis using waste cooking biodiesel fuel with an artificial neural network", Renew. Energ., 34, pp. 976-982 (2009).

24. Deh Kiani, M.K., Ghobadian, B., Tavakoli, T., Nikbakht, A.M., and Najafi, G. "Application of artificial neural networks for the prediction of performance and exhaust emissions in SI engine using ethanolgasoline blends", Energy, 35, pp. 65-69 (2010).

25. Togun, N.K. and Baysec, S. "Prediction of torque and specific fuel consumption of a gasoline engine by using artificial neural networks", Appl. Energy, 87, pp. 349355 (2010).

26. Kesgin, U. "Genetic algorithm and artificial neural network for engine optimisation of efficiency and NOx emission", Fuel, 83, pp. 885-895 (2004).

27. Homaifar, A., Lai, H.Y., and McCormick, E. "System optimization of turbofan engines using genetic algorithms", Appl. Math. Modelling, 18(2), pp. 72-83 (1994).

28. Manolas, D.A. "Operation optimisation of an industrial cogeneration system by a genetic algorithm", Energy Convers. Manage., 38, pp. 15-17 (1997).

29. Box, G. and Behnken, D. "Some new three level designs for the study of quantitative variables", Technometrics, 2, pp. 455-475 (1960).

30. Moffat, R.J. "Contributions to the theory of singlesample uncertainty analysis", ASME J. Fluids Eng., 104, pp. 250-260 (1982). 
31. Sayin, C., Ertunc, H.M., Hosoz, M., Kilicaslan, I., and Canakci, M. "Performance and exhaust emissions of a gasoline engine using artificial neural network", Appl. Therm. Eng., 27, pp. 46-54 (2007).

32. Çay, Y. "Prediction of a gasoline engine performance with artificial neural network", Fuel, 111, pp. 324-331 (2013).

33. Karaboga, D. "An idea based on honey bee swarm for numerical optimization", Technical Report-TR06, Erciyes University, Computer Engineering Department (2005).

34. Derakhshan, S., Pourmahdavi, M., Abdollahnejad, E., Reihani, A., and Ojaghi, A. "Shape optimization of a centrifugal pump impeller using artificial bee colony algorithm", Comput. Fluids, 81, pp. 145-151 (2013).

35. Celik, M.B. "Experimental determination of suitable ethanol-gasoline blend rate at high compression ratio for gasoline engine", Appl. Therm. Eng., 28, pp. 396404 (2008).

36. Porter, J.C. "Alcohol-water injection for high compression engines", SAE paper no. 500042 (1950).

37. Nicholls, J.E., EI-Messiri, I.A., and Newhali, H.K. "Inlet manifold water injection for control of nitrogen oxides theory and experiment", SAE paper no. 690018 (1969).

38. Weatherford, W.D. and Quillian, R.D. "Total cooling of piston engines by direct water injection", SAE paper no. 700886 (1970).

39. Lestz, S.S., Meyer, W.E., and Colony, C.M. "Emissions from a direct-cylinder water injected spark ignition engine", SAE paper no. 720113 (1972).

40. Nande, A.M., Wallner, T., and Naber, J. "Influence of water injection on performance and emissions of a direct-injection hydrogen research engine", SAE paper no. 2008-01-2377 (2008).

41. Brusca, S. and Lanzafame, R. "Water injection in IC-SI engines to control detonation and to reduce pollutant emissions", SAE Technical Paper, No. 200301-1912 (2003).

42. Heywood, J.B., Internal Combustion Engine Fundamentals, McGraw-Hill (1988).

43. Al-Hasan, M. "Effect of ethanol-unleaded gasoline blends on engine performance and exhaust emission", Energy Convers. Manage., 44, pp. 1547-1561 (2003).

44. Masumn, B.M., Masjuki, H.H., Kalam, M.A., Rizwanul Fattah, I.M., Palash, S.M., and Abedin, M.J. "Effect of ethanol-gasoline blend on NOx emission in SI engine", Renew. Sust. Energy Rev., 24, pp. 209-222 (2013).
45. Mazas, A.N., Lacoste, D.A., and Schuller, T. "Experimental and numerical investigation on the laminar flame speed of $\mathrm{CH}_{4} / \mathrm{O}_{2}$ mixtures diluted with $\mathrm{CO}_{2}$ and $\mathrm{H}_{2} \mathrm{O}$ ", ASME Turbo Expo, pp. 411-421 (2010).

46. Bouchard, C.L., Taylor, C.F., and Taylor, E.S. "Variables affecting flame speed in the otto-cycle engine", SAE Technical Paper No. 370184 (1937).

47. Eyidogan, M., Ozsezen, A.N., Canakci, M., and Turkcan, A. "Impact of alcohol-gasoline fuel blends on the performance and combustion characteristics of an SI engine", Fuel, 89, pp. 2713-2720 (2010).

48. Flagan, R.C. and Seinfeld, J.H., Fundamentals of Air Pollution Engineering, Courier Corporation (2013).

49. Wu, C.W., Chen, R.H., Pu, J.Y., and Lin, T.H. "The influence of air-fuel ratio on engine performance and pollutant emission of an SI engine using ethanolgasoline blended fuels", Atmos. Environ., 38, pp. 7093100 (2004).

\section{Biographies}

Borhan Beigzadeh received his $\mathrm{PhD}$ degree in Mechanical Engineering from Sharif University of Technology in 2011, working on dynamic walking systems and studying their correlation with dynamic passive/active manipulation systems. He then joined Iran University of Science and Technology (IUST) in Tehran, where he established Biomechatronics and Cognitive Engineering Research Laboratory, since then, he has been an Assistant Professor in the School of Mechanical Engineering. His research interests cover non-linear dynamics and control, robotics, biomechatronics, and cognitive engineering.

Amin Reihani received his BSc degree in Mechanical Engineering from Iran University of Science and Technology in 2014. He received his MSc degree in Mechanical Engineering from University of Michigan Ann Arbor - in 2015 and started PhD in Mechanical Engineering in 2016 at University of Michigan. His research interests include energy conversion/storage, and sustainability with applications in automotive engineering.

Ashkan Ojaghi received his BSc degree in Mechanical engineering from the Iran University of Science and Technology in 2014 and is currently an MSc student in the Department of Mechanical Engineering at York University, Canada. 